\title{
Determinação dos Períodos de Convivência da Cana-Soca com Plantas Daninhas ${ }^{1}$
}

\author{
Weed Interference Periods in Ratoon Sugarcane
}

\author{
MEIRELLES, G.L.S. ${ }^{2}$, ALVES, P.L.C.A. ${ }^{3}$ e NEPOMUCENO, M.P. ${ }^{4}$
}

\begin{abstract}
RESUMO - Esta pesquisa foi realizada com o objetivo de determinar o período anterior à interferência (PAI) e o periodo total de prevenção à interferência (PTPI) das plantas daninhas em cana-de-açúcar (cana-soca, segundo corte) do cultivar SP803280. O experimento foi instalado sobre um Latossolo Vermelho. Os tratamentos experimentais constituíram de periodos crescentes de controle ou de convivência das plantas daninhas com a cultura: 0 , 0-15, 0-34, 0-59. 0-90, 0-124, 0-157 e 0-269 dias (colheita da cana), totalizando 16 tratamentos, dispostos no delineamento de blocos ao acaso com quatro repetições. As plantas daninhas mais frequentes encontradas na área experimental foram: capim-colonião (Panicum maximum), carrapicho-de-carneiro (Acanthospermum hispidum) e apaga-fogo (Alternanthera tenella). Os resultados obtidos, admitindo-se 2 e 5\% de redução, na produção de colmos da cana-deaçúcar revelaram que o periodo anterior à interferência (PAI) tolerado pela cultura foi de 9 e 18 dias após a brotação (DAB), e o período total de prevenção à interferência (PTPI), de 200 e 137 DAB, respectivamente, resultando num período crítico de prevenção à interferência de 9 aos 200 DAB para $\%$ e 18 aos 137 DAB para 5\% de redução.
\end{abstract}

Palavras-chave: períodos de controle, competição, interferência, Saccharum spp.

ABSTRACT - The present work aimed to determine the period prior to interference and the total prevention period to interference of weeds in sugarcane (ratoon) cultivar SP 80-3280. The experiment was carried out on a Dark Red Oxisol. The treatments consisted of increasing periods of presence or absence of weeds: 0, 0-15, 0-34, 0-59. 0-90, 0-124,0-157, 0-269 days (sugarcane harvest). The most common weeds found in the experimental area were Panicum maximum, Acanthospermum hispidum and Altemanthera tenella. The results obtained, admitting $2 \%$ and $5 \%$ reduction in sugarcane productivity, showed that the period prior to interference tolerated by the culture was 9 and 18 days after ratoon sprout (DAS) and the total prevention period to interference was 200 and 137 DAS, respectively, resulting in a critical period of prevention to interference from 9 days at 200 DAS of $2 \%$ reduction, to 18 days at 137 DAS, of 5\% reduction.

Keywords: control periods, competition, interference, Saccharum spp.

\section{INTRODUÇÃO}

A infestação de plantas daninhas é um dos principais fatores bióticos presentes no agroecossistema da cana-de-açúcar capaz de interferir no desenvolvimento e na produtividade da cultura (Kuva et al., 2003). O termo interferência refere-se ao somatório de pressões que sofre uma determinada cultura em decorrência da presença de plantas daninhas no ambiente comum. Essas plantas podem competir por recursos limitantes do meio (principalmente água, luz e nutrientes), por liberar substâncias alelopáticas, podendo inibir a brotação da cana-de-açúcar, hospedar pragas e doenças comuns à cultura e,

1 Recebido para publicação em 24.1.2008 e na forma revisada em 18.2.2009.

2 Engo-Agr ${ }^{\circ},<$ meirellesg@hotmail.com>; ${ }^{3}$ Professor Adjunto, Dr., DBAA - FCAV/UNESP, Rod. Prof. Paulo Donato Castellane, s/n, 14884-900 Jaboticabal-SP, <plalves@fcav.unesp.br>, Bolsistas do CNPq; ${ }^{4}$ Eng ${ }^{\mathrm{a}}-\mathrm{Agr}{ }^{\mathrm{a}}$, M.Sc., Doutoranda em Produção Vegetal da FCAV-UNESP, Jaboticabal-SP, <mariluce_n@hotmail.com> 
sobretudo, interferir no rendimento da colheita (Pitelli, 1985). A presença única ou conjunta desses componentes de interferência negativa poderá causar reduções quali e quantitativa na cana-de-açúcar colhida, além de diminuir o número de cortes economicamente viáveis (Lorenzi, 1988).

O grau de interferência depende, entre vários fatores, da duração do período de convivência, da época em que este ocorre, que é modificado por elementos edáficos e climáticos, e dos tratos culturais empregados (Pitelli, 1985). É importante ressaltar que a interferência é um fenômeno recíproco, ou seja, a própria cultura tem potencial para limitar o desenvolvimento das plantas daninhas (Kuva et al., 2001), principalmente por meio do sombreamento nas entrelinhas.

São três os períodos críticos de interferência das plantas daninhas denominados por Pitelli \& Durigan (1984): período anterior à interferência (PAI), período total de prevenção à interferência (PTPI) e período crítico de prevenção à interferência (PCPI). Esses períodos determinam, em última análise, o período em que efetivamente os métodos de controle devem atuar.

Estudos sobre a interferência das plantas daninhas na produtividade da cana-de-açúcar foram realizados por diversos pesquisadores (Coleti et al., 1997; Kuva et al., 2001, 2003, 2007). A maioria dessas pesquisas teve como objetivo principal determinar a época e a extensão dos períodos de convivência tolerados pela cultura e, consequentemente, o período em que efetivamente os métodos de controle devem ser empregados. Os resultados obtidos foram diferentes, em decorrência, principalmente, das variações nas condições de cultivo em que foram conduzidas. Como existe grande diversidade de fatores que influenciam o grau e os períodos de interferência das plantas daninhas, torna-se importante a realização desses estudos com maior frequência e em diferentes locais e épocas do ano (Pitelli, 1985).

Esta pesquisa objetivou determinar o período em que a cultura da cana-de-açúcar pode conviver, desde sua brotação, com as plantas daninhas sem interferência negativa em sua produção final de colmos - PAI, bem como o período a partir da brotação em que a cultura deve permanecer livre da presença das plantas daninhas para que não ocorram perdas significativas de produção - PTPI. A partir desses períodos, determinar-se-á o período em que efetivamente os métodos de controle devem atuar para minimizar as perdas de produção - PCPI.

\section{MATERIAL E MÉTODOS}

A pesquisa foi realizada em novembro de 2002 no municipio de Batatais, SP, em área de produção comercial de cana-de-açúcar da Fazenda Nova Esperança. O cultivar utilizado no plantio foi o SP803280, de segundo corte. Foi feito o nivelamento do terreno ("quebra de lombo") com adubação de cobertura, utilizando-se $300 \mathrm{~kg} \mathrm{ha}^{-1}$ da fórmula comercial 21-0-20 (N-P-K).

Após a colheita da cana de primeiro corte, procedeu-se a uma amostragem composta de terra, que foi submetida às análises física e química de rotina, realizadas no Departamento de Solos e Adubos da FCAV-UNESP. O solo é um Latossolo Vermelho, com textura argilosa, apresentando $\mathrm{pH}$ de 5,6, $35 \mathrm{~g} \mathrm{dm}^{-3}$ de matéria orgânica e $68 \%$ de capacidade de saturação de bases.

Os tratamentos experimentais foram constituídos por dois grupos de convivência da cultura com a comunidade infestante. No primeiro, com início na brotação da cana, as plantas daninhas conviveram com a cultura por períodos crescentes. Após o término de cada período, foi realizado o controle das plantas daninhas com capina manual nas parcelas correspondentes, que foram mantidas no limpo até a colheita. No segundo grupo, as plantas daninhas foram controladas com capina manual por períodos crescentes, iniciados na brotação da cultura. No final dos períodos iniciais de controle, foi permitido que as plantas daninhas se desenvolvessem normalmente nas parcelas experimentais. Os períodos iniciais de convivência ou controle estudados foram: $0,0-15,0-34,0-59$, 0-90, 0-124, 0-157 dias após a brotação (DAB) e 0 até a colheita, totalizando 16 tratamentos.

O delineamento experimental adotado foi o de blocos (casualizados), com quatro 
repetições. As parcelas constaram de cinco linhas com $10 \mathrm{~m}$ de comprimento, totalizando $70 \mathrm{~m}^{2}$. As amostragens das plantas daninhas foram realizadas na área útil $\left(33,6 \mathrm{~m}^{2}\right)$ de cada parcela, deixando-se como bordadura uma linha de cana-de-açúcar de cada lado e $1 \mathrm{~m}$ em cada extremidade das três linhas centrais.

Nos tratamentos referentes aos períodos iniciais de convivência da comunidade infestante com a cultura, foram realizadas amostragens das plantas daninhas no final de cada período predeterminado. A área total amostrada, por parcela, foi de $1 \mathrm{~m}$ quadrado, composta por quatro subamostras de $0,25 \mathrm{~m}^{2}$ $(0,5 \times 0,5 \mathrm{~m})$, colhidas aleatoriamente. As partes aéreas das plantas daninhas encontradas nas subamostras foram coletadas e separadas por espécie. Foram determinadas a densidade e a matéria seca populacional. Nas parcelas dos períodos iniciais de controle da comunidade infestante, a amostragem das plantas daninhas foi realizada na época da colheita da cana. Para isso, também foi amostrado $1 \mathrm{~m}^{2}$ por parcela, tomado aleatoriamente, seguindo mesmo procedimento adotado para o outro grupo. Concomitantemente com as avaliações da comunidade infestante, foi determinada a altura de duas plantas de cana-de-açúcar na área útil das parcelas que permaneceram no limpo ou no mato. Essa altura foi determinada pela distância entre a superfície do solo e a última lígula visivel.

Os dados de densidade e matéria seca da comunidade infestante foram extrapolados para número de plantas e matéria seca por metro quadrado, respectivamente, e posteriormente submetidos à análise de regressão. Para escolha da equação de regressão, consideraram-se a lógica do fenômeno biológico, a significância da análise de variância da regressão e o valor do coeficiente de determinação, conforme procedimento adotado por Kuva et al. (2001).

Nos tratamentos com períodos iniciais de convivência foi realizada a análise fitossociológica da comunidade infestante, segundo procedimento descrito por Mueller-Dombois $\&$ Ellemberg (1974), sendo determinadas, para cada espécie, a frequência relativa, a densidade relativa, a dominância relativa e a importância relativa.

A cana-de-açúcar foi colhida manualmente após a queimada. A produção de colmos foi quantificada em dois metros lineares, na área útil de cada parcela, utilizando-se uma balança da Canduro Ltda de $25 \mathrm{~kg}$, apoiada em um tripé. Os dados obtidos foram extrapolados para toneladas de cana por hectare e, posteriormente, para porcentagem, considerandose como máxima (100\%) a produção obtida no tratamento em que as plantas daninhas foram controladas durante todo o período analisado.

Os dados de produção de colmos foram analisados separadamente, dentro de cada grupo (períodos iniciais de convivência ou de controle das plantas daninhas). Os resultados foram normalizados (percentuais) e submetidos à análise de regressão pelo modelo sigmoidal de Boltzman, conforme utilizado por Kuva et al. (2001). Este modelo obedece à seguinte equação:

$\mathrm{Y}=\mathrm{A}_{2}+\left[\left(\mathrm{A}_{1}-\mathrm{A}_{2}\right) /(1+\exp (\mathrm{X}-\mathrm{Xo}) / \mathrm{dx})\right], \mathrm{em}$ que $\mathrm{Y}$ é a produção estimada em colmos de cana-de-açúcar, em $\mathrm{kg} \mathrm{ha}^{-1}$; X, o limite superior do período de convivência ou controle considerado; $A_{1}$, a produção máxima estimada obtida nas parcelas mantidas no limpo durante todo o ciclo da cultura; $A_{2}$, a produção mínima estimada decorrente das parcelas mantidas no mato durante todo o ciclo; Xo, o período superior do período de convivência ou controle, que corresponde ao valor intermediário entre a produção máxima e a mínima; e dx, o parâmetro que indica a velocidade de perda ou ganho de produção ( $\operatorname{tg} \alpha$ no ponto Xo).

Com base nas equações de regressão, foram determinados os períodos de interferência das plantas daninhas para os niveis arbitrários de tolerância de 2 e $5 \%$ de redução na produção de colmos da cana-de-açúcar, em relação ao tratamento mantido na ausência das plantas daninhas.

\section{RESULTADOS E DISCUSSÃO}

A comunidade infestante, ao final dos períodos de convivência e controle, foi composta por 12 espécies: A. tenella (apaga-fogo), A. hispidum (carrapicho-de-carneiro), Bidens pilosa (picão-preto), Emilia sonchifolia 
(falsa-serralha), Parthenium hysterophorus (losna-branca), Commelina benghalensis (trapoeraba), Ipomoea grandifolia (corda-deviola), Euphorbia heterophylla (leiteiro), P. maximum (capim-colonião), Cenchrus echinatus (capim-carrapicho), Richardia brasiliensis (poaia-branca) e Nicandra physaloides (joá-de-capote). As espécies que se destacaram em importância relativa foram P. maximum, A. hispidum e A. tenella, em virtude da densidade e dominância relativas.

Considera-se de suma importância o reconhecimento das espécies de ocorrência nos diferentes locais, o conhecimento do seu hábito de crescimento, bem como a sua capacidade de competição e os riscos que possam oferecer, visando a estratégia mais eficiente e econômica para o seu controle, pois qualquer área que se encontra infestada ou invadida por plantas daninhas tem seu valor muito reduzido, especialmente se essas espécies forem perenes (Deuber, 1992; Kuva et al., 2008a). Kuva et al. (2007), estudando a fitossociologia de comunidades de plantas daninhas de 28 canaviais colhidos no sistema mecanizado, sem queima prévia da palha, constataram que Cyperus rotundus foi a principal espécie infestante, destacando-se quanto aos valores de importância relativa (IR). Resultado semelhante foi obtido por Oliveira \& Freitas (2008) realizando levantamento fitossociológico de plantas daninhas em áreas de produção de cana-de-açúcar em Campos de Goytacazes-RJ. As plantas dicotiledôneas anuais de propagação por sementes também se destacaram, entre as quais diversas espécies das famílias Euphorbiaceae e Convolvulaceae, tal qual observado por Kuva et al. (2008b) e Monquero et al. (2008).

Analisando os dados referentes à densidade total das plantas daninhas que compuseram a comunidade infestante (Figura 1), verificouse que o fluxo máximo de emergência foi observado aos 30 dias após a brotação (DAB), com 66 plantas $\mathrm{m}^{-2}$, após o qual constatou-se decréscimo, seguido de um novo fluxo ( 57 plantas $\mathrm{m}^{-2}$ ) aos 90 DAB. Após essa avaliação, houve redução na densidade populacional, tendo-se observado aos 157 DAB cerca de 20 plantas $\mathrm{m}^{-2}$.

As precipitações acumuladas $(1.200 \mathrm{~mm})$ nos três meses iniciais - dezembro, janeiro e fevereiro - da convivência da cultura com a comunidade infestante favoreceram o estabelecimento inicial das populações de plantas daninhas. Posteriormente, o aumento da competição, intra e interespecífica, provocou acentuada mortalidade das plantas, acrescido do encerramento do ciclo biológico de algumas plantas daninhas que haviam germinado no início da convivência com a cultura, especialmente A. hispidum, causando a redução da densidade total. Segundo Radosevich et al. (1997), à medida que se aumenta a densidade e o desenvolvimento das plantas daninhas, especialmente daquelas que germinaram e emergiram no início do ciclo de uma cultura, intensifica-se a competição inter e intraespecífica, de modo que as plantas daninhas mais altas e desenvolvidas tornam-se dominantes, ao passo que as menores são suprimidas ou morrem.

A matéria seca da parte aérea da comunidade infestante foi crescente em função do aumento dos períodos iniciais de convivência (Figura 2), ajustando-se à equação quadrática: $\mathrm{y}=0,0343 \mathrm{x}^{2}+2,3038 \mathrm{x}-41,764$, com coeficiente de determinação $\left(\mathrm{R}^{2}\right)$ de 0,9839 , acumulando $1.147 \mathrm{~g} \mathrm{~m}^{-2}$ aos $157 \mathrm{DAB}$.

Quanto à densidade da comunidade infestante em função dos períodos iniciais de controle, verificou-se que ela tendeu a diminuir em função do aumento dos períodos crescentes de controle, atingindo o mínimo de duas plantas $\mathrm{m}^{-2}$ aos 157 DAB (Figura 3). $\mathrm{O}$ ajuste matemático demonstrou que o

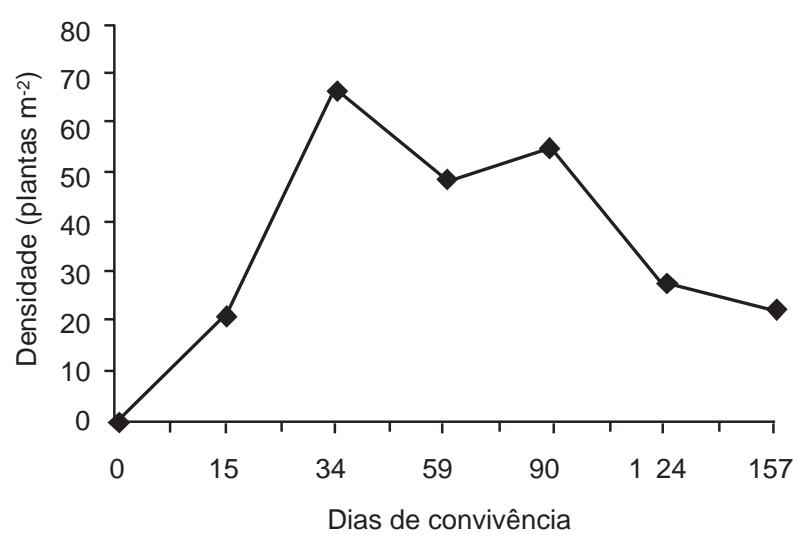

Figura 1 - Densidade total das plantas daninhas que compuseram a comunidade infestante em resposta aos dias de convivência com a cultura da cana-de-açúcar. Batatais, 2008 . 
comportamento da densidade foi quadrático, conforme a equação $\mathrm{y}=7 \mathrm{E}-05 \mathrm{x}^{2}-0,0279 \mathrm{x}+$ $4,9062\left(R^{2}=0,973\right)$.

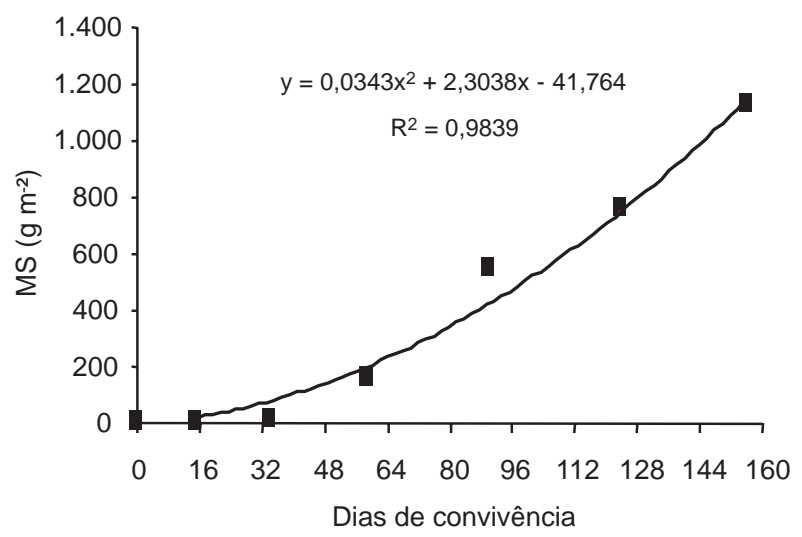

Figura 2 - Matéria seca (MS) total das plantas daninhas que compuseram a comunidade infestante em resposta aos dias de convivência com a cultura da cana-de-açúcar. Batatais, 2008 .

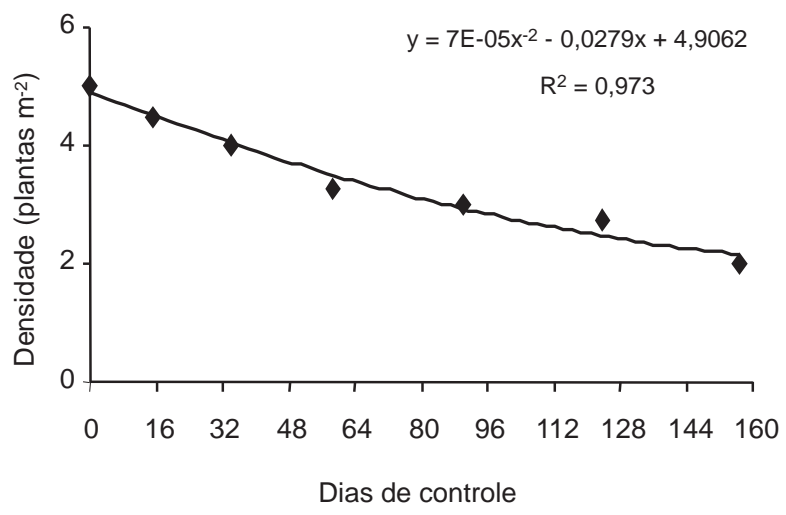

Figura 3 - Densidade total das plantas daninhas que compuseram a comunidade infestante em resposta aos dias de controle na cultura da cana-de-açúcar. Batatais, 2008.

Os valores de matéria seca acumulada pela comunidade infestante, na ocasião da colheita da cana-de-açúcar, em função dos períodos iniciais de controle, estão apresentados na Figura 4. Com o aumento dos períodos de controle, a matéria seca acumulada pela comunidade infestante tendeu a apresentar decréscimo exponencial $\left(\mathrm{y}=414,79 \mathrm{e}^{-0,0228 \mathrm{x}} \mathrm{e}\right.$ $\left.\mathrm{R}^{2}=0,877\right)$. O período de controle de $59 \mathrm{DAB}$ já foi suficiente para reduzir consideravelmente o acúmulo de matéria seca pela comunidade infestante; após esse período, o acúmulo se manteve constante, em torno de $23 \mathrm{~g} \mathrm{~m}^{-2}$.
Esse resultado contraria o obtido por Coleti et al. (1997), que constataram reinfestação após longos períodos de controle.

Quando o controle das plantas daninhas foi realizado durante todo o ciclo da cultura, a produção obtida para a cana-de-açúcar plantada na área experimental de Batatais foi de 126,8 $\mathrm{t} \mathrm{ha}^{-1}$. Quando não houve o controle da comunidade infestante, ocorreu perda de $33,4 \%$ na produtividade da área.

Entre as plantas daninhas presentes na área, o capim-colonião se destacou por apresentar maior dominância relativa, acumulando aos $157 \mathrm{DAB}$ cerca de $900 \mathrm{~g} \mathrm{MS} \mathrm{m}^{-2}$. Estudo conduzido em área de cana-de-açúcar, com infestação de capim-colonião, apresentou perdas de produção superior a 29\% (Gravena et al., 2001), similar à observada em Batatais, quando não foi realizado o controle das plantas daninhas. As plantas dessa espécie apresentam ciclo perene (Kissmann \& Groth, 1992), o que permite que convivam com cana-deaçúcar desde o plantio até a colheita, causando intensa interferência competitiva. Além da competição por recursos de crescimento, também é possível que ocorra interferência alelopática dessa planta daninha sobre a cana-deaçúcar, conforme observado em plantas cultivadas (Souza et al., 2003). É importante destacar que as plantas de capim-colonião, por apresentarem grande porte na ocasião da colheita, também podem interferir indiretamente na rentabilidade da cultura, prejudicando a colheita, o transporte e o processamento da cana (Kissmann \& Groth, 1992).

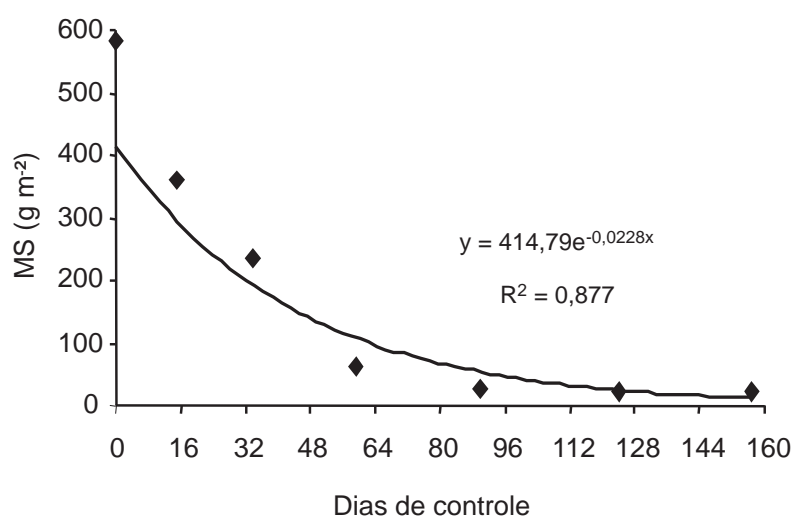

Figura 4 - Matéria seca (MS) total das plantas daninhas que compuseram a comunidade infestante em resposta aos dias de controle na cultura da cana-de-açúcar. Batatais, 2008. 
Na Figura 5 estão apresentadas as produções percentuais de colmo de cana-de-açúcar em função da extensão do período inicial de convivência ou do controle das plantas daninhas. Os dados obtidos se ajustaram de forma adequada à equação de Boltzman, com $\mathrm{R}^{2}=0,9877$ (Tabela 1 ). Os períodos críticos de convivência e controle das plantas em função dos niveis arbitrários de 2 e 5\% de tolerância (Tabela 2) na redução da produção da cultura foram determinados a partir das equações de regressão.

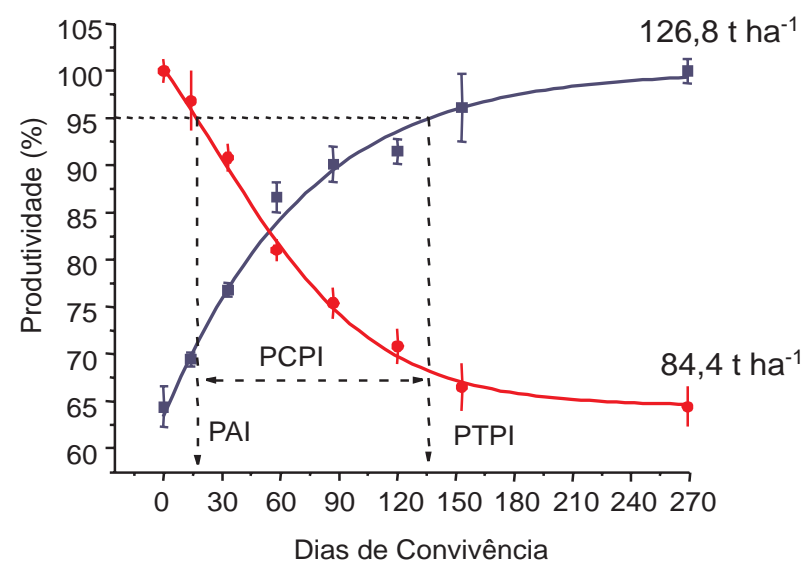

Figura 5 - Produção percentual da cana-de-açúcar, observada (símbolos) e estimada pela equação sigmoidal de Boltzman (linhas), em função dos períodos iniciais de convivência ou controle das plantas daninhas. Batatais, 2008.
Admitindo como aceitável uma perda máxima de $5 \%$ na produção de colmos da cana-soca, constatou-se que a cultura pôde conviver com a comunidade infestante até $18 \mathrm{DAB}$, sendo esse período denominado de período anterior à interferência (PAI). Para esse mesmo nível de tolerância, foi determinado que é necessário controlar as plantas daninhas até $137 \mathrm{DAB}$, sendo esse período denominado de período total de prevenção à interferência (PTPI). O intervalo entre o PAI e o PTPI define o período crítico de prevenção à interferência (PCPI), que corresponde ao período no qual as práticas de controle devem ser efetivas para evitar perdas significativas em produção. Dessa forma, o PCPI em Batatais, para cana-soca, foi de 18 a 137 DAB.

Analisando os resultados obtidos no presente estudo e os observados na literatura, para a cana-soca, constata-se que o período anterior à interferência obtido foi menor que o determinado por Gravena et al. (2001), que foi de 28 DAB. O período total de prevenção à interferência determinado por esses pesquisadores foi de 58 DAB. Resultados similares foram obtidos em dois experimentos conduzidos por Kuva et al. (2000, 2001 e 2003), nos quais os periodos de controle exigidos foram de 127 e 140 dias após o plantio. Segundo Pitelli (1985), a duração do PTPI pode ser influenciada principalmente pela intensidade

Tabela 1 - Parâmetros determinados para as equações sigmoidais de Boltzman ajustadas aos dados de produção percentual da canade-açúcar em função dos períodos de convivência ou controle das plantas daninhas. Batatais, 2008

\begin{tabular}{|c|c|c|c|c|c|}
\hline Condição (períodos) & $\mathrm{A}_{1}$ & $\mathrm{~A}_{2}$ & $\mathrm{x}_{0}$ & $\mathrm{~d}_{\mathrm{x}}$ & $\mathrm{R}^{2}$ \\
\hline Convivência & 119,57 & 64,209 & 28,309 & 43,596 & 0,9959 \\
\hline Controle & $-214,4$ & 99,939 & $-134,79$ & 65,938 & 0,9877 \\
\hline
\end{tabular}

Tabela 2 - Período anterior à interferência (PAI), período total de prevenção à interferência (PTPI) e período crítico de prevenção à interferência (PCPI), calculados pelas equações sigmoidais para dois níveis de tolerância nas perdas de produtividade da canade-açúcar. Batatais, 2008

\begin{tabular}{|c|c|c|c|}
\hline \multirow{2}{*}{ Nível de Tolerância (\%) } & \multicolumn{2}{|c|}{ Período determinado para cada nível de tolerância (dias após a brotação) } \\
\cline { 2 - 4 } & PAI & PTPI & PCPI \\
\hline 2 & 9 & 200 & $18-200$ \\
\hline 5 & 18 & 137 & 137 \\
\hline
\end{tabular}


e pela velocidade em que ocorre o sombreamento das entrelinhas pela cultura. Quanto maior a intensidade e velocidade de sombreamento, menor tende a ser o PTPI.

Considerando uma perda de até $5 \%$ na produção, pode-se concluir que a cultura da cana-de-açúcar SP803280 (cana-soca) pode conviver com uma comunidade infestante com predominância de $A$. hispidum, $A$. tenella e $P$. maximum até $18 \mathrm{DAB}$. O PTPI foi de até $137 \mathrm{DAB}$, e o PCPI, no período de 18 aos $137 \mathrm{DAB}$. No caso de $2 \%$ de perda na produção, o PAI tolerado pela cultura foi de $9 \mathrm{DAB}$, e o PTPI, de 196 DAB, resultando num PCPI no período de 9 aos $196 \mathrm{DAB}$.

\section{LITERATURA CITADA}

COLETI, J. T. et al. Brachiaria pode provocar sérios danos nos canaviais. Inf. Coopercitrus, n. 132, p. 34-35, 1997.

DEUBER, R. Ciência das plantas daninhas: fundamentos Jaboticabal: FUNEP, 1992. 431 p.

GRAVENA, R.; KUVA, M. A.; PITELLI, R. A. Períodos de interferência de plantas daninhas em soqueira de cana-deaçúcar (Saccharum spp.). In: CONGRESSO DE LA ASSOCIACIÓN LATINO AMERICANA DE MALEZAS, 15., 2001, Maracaibo. Resumos... Maracaibo: SOVECOM, 2001. p. 102

KISSMANN, K. G.; GROTH, D. Plantas infestantes e nocivas. São Paulo: BASF, 1992. 798 p

KUVA, M. A. et al. Períodos de interferência das plantas daninhas na cultura da cana-de-açúcar. I - Tiririca (Cyperus rotundus). Planta Daninha, v. 18, n. 2, p. 241-251, 2000.

KUVA, M. A. et al. Períodos de interferência das plantas daninhas na cultura da cana-de-açúcar. II - Capim-braquiária (Brachiaria decumbens). Planta Daninha, v. 19, n. 3, p. 323-330, 2001

KUVA, M. A. et al. Períodos de interferência das plantas daninhas na cultura da cana-de-açúcar. III - capim-braquiária (Brachiaria decumbens) e capim-colonião (Panicum maximum). Planta Daninha, v. 21, n. 1, p. 37-44, 2003.
KUVA, M. A. et al. Fitossociologia de comunidades de plantas daninhas em agroecossistema cana-crua. Planta Daninha, v. 25, n. 3, p. 501-511, 2007.

KUVA, M. A. et al. Padrões de infestação de comunidades de plantas daninhas no agroecossistema cana-crua. Planta Daninha, v. 26, n. 3, p. 549-557, 2008 a.

KUVA, M. A. et al. Banco de sementes de plantas daninhas e sua correlação com a flora estabelecida no agroecossistema cana-crua. Planta Daninha, v. 26, n. 4, p. 735-744, 2008b

MONQUERO, P. A. et al. Mapas de infestação de plantas daninhas em diferentes sistemas de colheita da cana-deaçúcar. Planta Daninha, v. 26, n. 1, p. 47-55, 2008

MUELLER-DOMBOIS, D.; ELLEMBERG, H. Aims and methods of vegetation ecology. New York: John Willey \& sons, 1974. $547 \mathrm{p}$.

OLIVEIRA, A. R.; FREITAS, S. P. Levantamento fitossociológico de plantas daninhas em áreas de produção de cana-de-açúcar. Planta Daninha, v. 26, n. 1, p. 33-46, 2008

PITELLI, R. A. Interferência de plantas daninhas em culturas agrícolas. Inf. Agropec., v. 11, n. 129, p. 16-27, 1985

PITELLI, R. A.; DURIGAN, J. C. Terminologia para períodos de controle e convivência das plantas daninhas em culturas anuais e bianuais. In: CONGRESSO BRASILEIRO DE HERBICIDAS E PLANTAS DANINHAS, 15., 1984, Belo Horizonte. Resumo... Belo Horizonte: SBHPD, 1984. p. 37.

PROCÓPIO, S. O.; SILVA, A. A.; VARGAS, L. Manejo e controle de plantas daninhas em cana-de-açúcar. In: VARGAS, L.; ROMAN, E. S. (Eds.). Manual de manejo e controle de plantas daninhas. Bento Gonçalves: Embrapa Uva e Vinho, 2004. p. 397-452.

RADOSEVICH, S. R.; HOLT, J.; GHERSA, C. Weed ecology: Implications for vegetation management. New York: John Wiley \& sons, 1997. 263 p

SOUZA, L. S.; VELINI, E. D.; MAIOMONI-RODELLA, R. C. S. Efeito alelopático de plantas daninhas e concentrações de capim-braquiária (Brachiaria decumbens) no desenvolvimento inicial de eucalipto (Eucalyptus grandis). Planta Daninha, v. 21, n. 3, p. 343-354, 2008 